\title{
Loneliness Among Older Home-Dwelling Persons: A Challenge for Home Care Nurses
}

This article was published in the following Dove Press journal:

Journal of Multidisciplinary Healthcare

\section{Solveig Tomstad (D) \\ Kari Sundsli $\mathbb{D}$ \\ Hans Inge Sævareid D \\ Ulrika Söderhamn (D)}

Centre for Caring Research, Faculty of Health and Sport Sciences, University of Agder, Grimstad, Norway
Correspondence: Solveig Tomstad Faculty of Health and Sport Sciences, University of Agder, Kristiansand, 4604, Norway

Email solveig.t.tomstad@uia.no
Aim: To explore how nurses working in the home care service sector perceived the loneliness experienced by older people living at home, and how they met these lonely individuals' needs.

Background: Loneliness is a well-known phenomenon among groups of older homedwelling people and has been shown to be a health-related problem. Health care professionals working in the primary care sector, such as home care nurses, may be in the position to identify loneliness among at-home seniors. Identifying and addressing loneliness must become important issues in home care nursing.

Design: A qualitative study.

Methods: Focus group interviews were performed with 11 home care nurses in Norway. The interviews were analyzed in accordance with manifest and latent content analysis. The Coreq checklist was followed.

Findings: Home care nurses identified loneliness among older people as being a complex and sensitive phenomenon that activated conflicted thoughts, feelings and solutions in a system where older people's loneliness was generally not considered as a need requiring nursing care.

Conclusion: Loneliness among older people challenged the nurses with regard to communicating older people's feelings of loneliness and meeting their social needs. Organizational structures were perceived as being the main barriers to meeting these needs. Older people's feelings of loneliness stimulated nurses' reflections about the purpose of their nursing role. It is important to address loneliness among older home-dwelling people and include the issue in home care nursing in order to meet their need for social contact. Home nursing leaders must pay attention to the nurses' experiences, promote the nurses' acquisition of knowledge about this kind of loneliness and learn how to meet an older individual's needs. There should be a special focus on communicating with lonely older people in order to address their feelings loneliness.

Keywords: content analysis, focus group interview, home care nursing, home living, older people, qualitative research study

\section{Introduction}

Previous quantitative studies have shown that groups of older people living in their own home often feel lonely. ${ }^{1-3}$ Loneliness among older home-dwelling people has been shown to be a health-related state that may include social aspects as well as psychological and physical factors, such as having limited contact with neighbors, reduced mental health, being at nutritional risk, and not being able to handle negative feelings. ${ }^{3}$ Older people have reported struggling against obstacles to overcoming loneliness. ${ }^{4,5}$ These obstacles include their aging bodies, feeling 
unsafe, and not having the social support they need. ${ }^{5}$ Consequently, several older individuals may need support from health care professionals to cope with their loneliness. ${ }^{3}$

The literature has described loneliness as including feelings of suffering when there is a discrepancy between the reality of the individual's social connections and their wish to be socially involved. This also means there may be an element of "self-evaluation" when people experience loneliness. ${ }^{6}$ The topic of loneliness as a subjective experience is well known in the literature. ${ }^{7}$ Further, Weiss promoted two central aspects concerning feelings of loneliness: lacking a feeling of belonging with regard to other people and/or lack of social contacts. ${ }^{8}$ However, social isolation has been described in a review ${ }^{9}$ as the objective lack of contact with other persons. Loneliness was described as a person's perception of being social isolated and feeling lonely. ${ }^{9}$

In several European countries, health care professionals in primary care services may hold essential positions for identifying older individuals' needs and are important agents for meeting these needs. ${ }^{10}$ Many older home-dwelling persons in Norway receive help and support from home care nurses. ${ }^{11}$

The official political stance in Norway is that older people are to live in their own homes for as long as possible. ${ }^{12}$ Consequently, several older people live alone in their own residences. ${ }^{13}$ Community health care services in Norway are probably the most important official agency for meeting the care needs of older home-dwelling people. ${ }^{14}$ The Norwegian Health Care $\mathrm{Act}^{15}$ emphasizes that these services support every individual's opportunity to live independently, be active, and be able to spend time with other people.

Home care nurses have stated that they are responsible for making the administrative decisions about home care nursing for each service user. ${ }^{16,17}$ However, this approach to nursing may have been guided by an estimated timeframe to be spent with each service user, based on providing the minimum amount of care. As a result, the human aspect of care, such as meeting social needs, was perceived by the nurses to have been lost. ${ }^{16}$

A qualitative study ${ }^{18}$ showed that health care professionals in home care settings with lonely older people found it difficult to meet those people's needs. It is argued that addressing loneliness as a significant issue in health care settings is one of the most important steps to take in order to be able to meet older people's social needs. ${ }^{19}$ Therefore, it is important to conduct a study that focuses on home care nurses' experiences of working with lonely older home-dwelling persons and how they manage to take care of these individuals.

\section{Aim}

The aim of the study was to explore how nurses working in the home care service sector perceived the loneliness experienced by older people living at home, and how they met these lonely individuals' needs.

\section{Materials and Methods}

The study has a qualitative design based on three focus group interviews with home care nurses.

\section{Recruitment and Participants}

A cooperative agreement was reached with the Center for Development and Home Care Services in southern Norway. Contacts at this center introduced the study authors to three home care services first line managers in two municipalities. These leaders informed the home care nurses about the study. To be included in the study, informants had to be a registered nurse working in home care nursing and to have experience in providing nursing care to older service users living at home. A total of 16 home care nurses expressed interest in participating in the focus group interviews. However, five of these nurses could not attend these interviews due to their heavy workloads; thus, 11 informants were included in the study: three informants in one interview and four in each of the two others. All of the informants were women, ranging in age from 26 to 55 years old. They all had several years of professional nursing experience except for one informant, who had only worked as a nurse for one year. The nurses worked in purchaser-provider settings and were given estimated timeframes for each service user; in addition, their nursing was based on decisions that had been made by a purchaser team.

\section{Data Collection}

Two focus group interviews were conducted at the end of 2015, and a third one was conducted at the beginning of 2016. The interviews took place in the offices of the home care services. Three of the study authors (ST, HIS, US) conducted the data collection. One of the authors (ST) participated in each interview and was responsible for ensuring each of the interview's progression. The methodological approach to the focus group interviews allowed informants to speak openly about their perceptions of loneliness among older service users. An interview guide was used, which included the following questions: Please 
tell us about your perceptions of loneliness among the older people at your workplace. How do you identify lonely older people? What do you perceive as being important for meeting older people's needs for social belonging and social contact? What kinds of opportunities do you have for meeting these needs? Follow-up questions were raised based on the informants' responses. On average, each interview lasted a total of 72 minutes, and all interviews were audio recorded and transcribed verbatim.

\section{Analysis}

The transcribed texts were analyzed in accordance with the manifest and latent content analysis described by Graneheim and Lundman. ${ }^{20}$ The first step was to read the entire text of each interview in order to obtain a general sense of its content. In the manifest analysis the texts were then reread and divided into meaning units. These units were then condensed and abstracted using codes. The next step involved comparing the various codes in the three focus group interviews and creating categories that shared commonalities. Examples from the manifest analysis are presented in Table 1.

Six categories emerged in the manifest analysis, which refers to the descriptive level of the content:

- Loneliness - an individual and multifaceted experience

- Loneliness - difficult to talk about

- Loneliness - not generally accepted as a need for nursing care

- Loneliness - requiring simultaneous work

- Loneliness - the daycare center as a social initiative for older people
- Loneliness - a challenge that activates reflections on nursing

In the latent analysis an overall theme was interpreted based on the manifest content found in the categories. ${ }^{20}$

\section{Ethical Considerations}

The study was approved by the Norwegian Centre for Research Data (Norwegian Social Science Data Services) (project number 40064). One of the researchers (ST) gave oral and written information to the home care nurses and introduced the researchers before the interviews started. The informants were assured that their participation was voluntary and that they could withdraw from the study at any time..$^{21,22}$ The study was performed in accordance with the Declaration of Helsinki. ${ }^{22}$ All the informants gave their written consent to participate in the study and consent to publish data. The Coreq checklist $^{23}$ was used as a guide for reporting this qualitative study.

\section{Findings}

\section{The Overall Theme}

Loneliness among older people was perceived by the home care nurses as a complex and sensitive phenomenon that activates conflicted thoughts, feelings, and solutions in a system where loneliness is generally not regarded as a need for nursing care.

\section{Loneliness - An Individual and Multifaceted Experience}

The informants perceived that older people's feelings of loneliness were related to their individual experiences, such as being disconnected from others and going

Table I Examples of the Manifest Analysis

\begin{tabular}{|l|l|l|l|}
\hline Meaning Unit & Condensed Meaning Unit & Code & Category \\
\hline $\begin{array}{l}\text { I do not think l'd dare to ask somebody: Are you } \\
\text { lonely? I think l'd hurt their feelings if I did that } \\
\text { because people are usually very sensitive. We } \\
\text { know they are lonely, and if I ask: Are you lonely?, } \\
\text { that will just make them sad ... I'd rather ask: }\end{array}$ & $\begin{array}{l}\text { Not asking directly about loneliness because } \\
\text { such questions may hurt the older person's } \\
\text { feelings and make them sad. }\end{array}$ & $\begin{array}{l}\text { Not asking directly } \\
\text { about loneliness }\end{array}$ & $\begin{array}{l}\text { Loneliness - } \\
\text { difficult to } \\
\text { talk about } \\
\text { When was the last time you had a visitor? Or: }\end{array}$ \\
\hline $\begin{array}{l}\text { I think our opportunity lies in just using the time } \\
\text { we have. Paying attention, even though we have to } \\
\text { go around doing other things at the same time. It } \\
\text { can still be quality time. }\end{array}$ & $\begin{array}{l}\text { The opportunity lies in using the time well at the } \\
\text { visits, paying attention to the older people while } \\
\text { performing other tasks at the same time. }\end{array}$ & $\begin{array}{l}\text { To use the time well at } \\
\text { the vits and do several } \\
\text { things at the same time. }\end{array}$ & $\begin{array}{l}\text { Loneliness - } \\
\text { requiring } \\
\text { simultaneous } \\
\text { work }\end{array}$ \\
\hline
\end{tabular}


unnoticed. Assessing loneliness based on how many hours the older person was alone was not considered to be an adequate measurement. The nurses' preconceptions of who was lonely were not necessarily correct. The informants stressed that it was the older people's subjective experiences of loneliness that counted. Some individuals enjoyed living alone and were satisfied with receiving brief visits from home care nurses and seemed to feel well. Other older people often felt lonely when they were alone, and the informants perceived that some of them were lonely despite frequent visits from their home care nurses or having a large social network.

I think their personalities are very different. Some enjoy living on their own. They're happy to see us even though we're only there a quarter of an hour at a time. While others will feel lonely in spite of how often we visit them.

(Focus group 1, Informant C)

Informants noted that the younger seniors usually had more friends and participated in more social activities than the very old seniors. Loneliness among the older people may depend on their level of contact with family members. Missing other people and family members, such as spouses and siblings, may be one important aspect of loneliness. The informants perceived that, following bereavement, some individuals may miss their deceased spouse for several years, and so they longed to have other people around with whom they could talk so they would not feel lonely.

The informants also expressed that the older seniors with physical disabilities or who were in poor physical health may have limited social lives. For example, if older people are immobile, they might regard themselves as being at the mercy of other people's decision to visit them or not. A loss of vision and/or hearing may also cause feelings of loneliness to arise because the individual would not be able to watch TV, read the newspaper, or do any household chores, activities which could help relieve their feelings of loneliness.

The informants also perceived that older people with a cognitive disability like dementia may have a constant feeling of loneliness. These people often told their nurses that nobody ever visited them, even though in many cases this was simply not true. The informants wondered about the feelings of loneliness that people with dementia might have.

It was also expressed that older people's sense of loneliness could sometimes relate to their feeling of being unsafe. For example, it may not have been their wish to live alone in their own home.

Some seniors do not want to live alone. However, in our municipality this is the way this is settled. The older persons shall live in their own homes. (Focus group 1, Informant C)

A view expressed in the interviews was that when seniors living at home began to fear the evening's approach, this was the time to think about living with others so they could feel better. However, at the same time it was said that living in a nursing home was reserved for the very old who were ill and perhaps close to death.

Another aspect revealed was that older people who often experienced depression tended to be lonely, and loneliness might lead to depression. The informants therefore pointed out that it was important to focus on older people's mental health.

\section{Loneliness - Difficult to Talk About}

The informants often experienced older people expressing their loneliness in an indirect way. Some seniors wanted the nurses to stay longer during their home care visit, asking questions such as: "Do you have to leave already?" or "When will you come back?" Several informants said that these questions were asked daily. Other seniors tried to keep the conversation going with their nurse by raising new questions when the latter was getting ready to leave, perhaps inviting the nurse to stay and have a cup of coffee. The informants perceived that the service users wanted to keep talking with the nurses just to have somebody to talk to. This action was described as the predominant distinctive feature of loneliness. Several informants stated that they did not usually ask the older people directly about loneliness. One point of view was that these nurses were not in a position to deal with the consequence of asking their older service users this question. If the nurses simply asked the older persons how they were feeling that day, they would have to be prepared to talk for a while with them and set aside time for this communication.

... If you ask a person whether he or she is lonely, you can't get up and leave after two minutes. You have to know that you'll have enough time to talk about it. (Focus group 3, Informant C)

Consequently, nurses may avoid asking these kinds of questions. The informants also reflected on the thought 
that older people might feel that being lonely could make them appear unsuccessful, so they may find loneliness difficult to talk about. Being lonely was perceived as a kind of social taboo.

Loneliness may be perceived as a taboo subject. There are a few ... not everyone wants to say out loud that they're lonely. It's a negatively charged word. Perhaps someone who feels lonely sees him-/herself as being unsuccessful. (Focus group 2, Informant B)

Being aware of timing when talking about loneliness was perceived to be as important as not using the word "lonely." The informants said that they asked about loneliness indirectly when identifying the older individual's social situation.

I don't think I'd dare to ask somebody: Are you lonely? I think I'd hurt their feelings if I did that because people are usually very sensitive. We know they're lonely, and if I ask: Are you lonely? That will just make them sad ... I'd rather ask: When was the last time you had a visitor? Or: Have you been outside today? (Focus group 3, Informant A)

Sometimes the older people would tell the nurse about their loneliness without being asked or, on the contrary, would say they are not lonely yet show in their nonverbal behavior that they felt the opposite. When the nurses observed changes in the older people that included displaying higher levels of anxiety, depression, or loss of appetite, they might have taken steps to improve the older people's social situation. However, the informants reflected on the idea that feeling lonely could become less of a taboo subject if nurses practiced more direct communication.

\section{Loneliness - Not Generally Accepted as a Need for Nursing Care}

The home care nursing sessions mainly included the performance of practical duties. The informants perceived that it was usually physical needs that qualified for home care nursing and not feelings of loneliness. The informants shared that they previously could visit older people just to talk with them, but this situation had changed.

... previously, we made case-by-case decisions about home care visits so that we could help people deal with their feelings of loneliness. It's uncertain whether or not all their needs were met, but at least we had time to sit down with them for a little while ... That isn't the case now. (Focus group 1, Informant D)
Social supervision visits were most often reserved for older individuals with mental health issues or dementia. The informants said that they usually had no time allotted for sitting down and talking with anyone, as talking was not considered to be a nursing task. The informants perceived that this was mainly on the basis of the assessments performed by the purchaser team, which made the decisions regarding home care nursing tasks.

It's not always an easy situation, and when we ask for more time ... our request gets analyzed, and I feel they don't quite understand it. It'd be fine if the purchaser team's staff members could travel around and really see what it's like. We're the ones who are in the situations and see these older people. (Focus group 3, Informant A)

From an overall nursing perspective, this made the informants feel that they were not always providing people with total care. Consequently, the nurses sometimes made the decision to take the time to sit down and talk with the older individuals who disliked being alone.

If that happens, I often take "illegal steps" if I know I have time for it. I spend more time with the patient I perceive as being alone. We can't always do this, but sometimes we can meet their needs, although we don't have permission to do so. (Focus group1, Informant D)

The informants reported that sometimes visits were canceled, meaning they could spend this unoccupied time on other people who needed conversation. Another way of spending more time with lonely seniors was to find reasons for performing medical procedures, such as administering medication.

We have an opportunity to see patients more often if we can administer their medications every day. We can then find other reasons to visit them more often. (Focus group 1, Informant C)

The informants found it difficult to accept a system where the time schedule was so strictly regulated that the nurses' own assessments of their service users' needs could be disregarded. One viewpoint was that nurses could make their own assessments about what their service users needed to a certain degree; however, despite this leniency, nurses could not always complete their nursing tasks in accordance with administrative policy.

You can hardly act in accordance with administrative policy all the time. (Focus group 3, Informant A) 
However, the nurses who worked in full-time positions and had permanent schedules were allowed more opportunities to regulate their own time regarding home care visits.

\section{Loneliness - Requiring Simultaneous Work}

Nurses took steps to deal with their older service users' loneliness. These included talking with them and paying attention to their nonverbal communication while performing practical tasks.

I think our opportunity lies in just using the time we have. Paying attention, even though we have to go around doing other things at the same time. It can still be quality time.

(Focus group 1, Informant C)

The nurses had to be both physically and mentally present while communicating with the older people and listening to them, for example, by sitting down and taking off their jacket before giving service users their medication. This simple action signaled that they had time to spend with these people, even though they actually did not have this time. The informants also perceived that they could talk with the older people and pay attention by maintaining eye contact with them while performing their practical tasks. This would mean that they did not need to sit down and have a cup of coffee afterwards.

If you're helping someone take a shower, you can do a lot - good conversation, observations, and things like that during situations you're already doing. (Focus group 2, Informant A)

Nurses also spent a lot of time helping several older people with complex needs. This situation made it easier for these service users to confide in and form relationships with their professional nurses, which could give them a feeling of belonging and help relieve their loneliness. On the other hand, the informants perceived that they had to use their time well when visiting seniors who were assessed as having less complicated needs and so had been allotted limited time for home visits.

It's hard if you know that there's someone who's getting help from us every 14 days, and you only give the medicine. Then you know that you have to spend some time on your visit. You know that this person may not be seeing anybody else for 14 days. It's not a good feeling. (Focus group 1, Informant D)
There were also situations where a nurse provided company at meals for older service users who needed this to get enough food intake because there was nobody else who could provide this service. Similarly, one of the informants revealed that a nurse had sometimes been the last contact person for an older service user before they died, as there were no family members to contact. These experiences inspired the informant to sometimes take her lunch or dinner break with service users in need of company.

\section{Loneliness - The Day Care Center as a Social Initiative for Older People}

The informants revealed that they tried to motivate older service users on a daily basis to visit their local day care center to spend time with other people of their age. They said that several older people enjoyed participating at these centers; they not only calmed down but also made fewer phone calls to the nurses.

However, the informants also experienced several of the older service users feeling that they did not fit in with the other people at the center. Others were ambivalent about seeking out social contact and were reluctant to meet new people, so preferred visits from the home care nurses.

The informants said that older people's participation at their local day care center was the most important service provided for them. However, their observation that day care centers were not suitable for every older service user made them wish they could provide more individualized social initiatives. Some of the informants said that while they themselves were unable to organize older people's activities, they felt that they could do a better job of making suggestions to these people.

I think our job is to identify their needs, and in a way lead them, and be facilitators so they can get the help they need. But we can't meet all the users' needs ... (Focus group 2, Informant C)

\section{Loneliness - A Challenge That Activates Reflections on Nursing}

Several of the informants emphasized the point that they had been trained to take a general approach to nursing. The idea of being open to all the service users' needs, including their feelings of loneliness, was felt to be 
overwhelming for nurses, and it activated their reflections on the role of health care services in people's lives.

At times we feel that we're supposed to be open to meeting all user needs, and we're supposed to help when people are lonely, too. This has activated a discussion about what a community health care service is supposed to do. (Focus group 2, Informant C)

The nurses did not perceive themselves as social workers and expressed that other professionals had to become involved to provide service users with help and support. The informants perceived there to be potential for involving volunteers. However, several of them were unsure about how to involve volunteers to meet older people's social needs. They reflected on how volunteers could provide support for the older persons to participate in social activities with which they were familiar.

There were various reflections on whether or not regulated nursing services were useful. Some of the informants pointed out that there was something wrong with the policies made about nursing when preference was given to providing service users with only physical support. Other informants expressed that these policies were not barriers to meeting service users' needs and that these regulated nursing policies could not cancel out nurses' own professional assessments. A point of view was that since the nurses were not a homogeneous group, it was useful that other professionals (the purchaser team) made decisions pertaining to service users, as this process would ensure that service users would get the help for which they were qualified. At the same time, the informants stressed the importance of having professionals be knowledgeable about home care nursing. Moreover, some of the informants missed having more time for exchanging professional reflections.

... I think we lose professional aspects of home care nursing practice as well as quality and development, which disappear if we aren't given the opportunity to discuss things. (Focus group 2, Informant A)

\section{Discussion}

Loneliness among older people was perceived by the home care nurses as a complex and sensitive phenomenon that activates their conflicted thoughts, feelings, and solutions in a system where loneliness is generally not regarded as a need for nursing care. In the following section we will discuss this overall theme.
The home care nurses recognized the phenomenon of loneliness as related to various situations and factors that included social, psychological, and physical barriers or feelings of being left behind. The complexity of loneliness among older people is well known, ${ }^{1-3,24}$ as well as highlighted as a health-related problem among a group of older people living at home. ${ }^{3}$

The nurses in the current study described loneliness among the older persons in accordance with negative emotions, which are individual experiences. Feeling lonely may indicate that a person is living in an imposed situation that is experienced as undesirable. ${ }^{6,9}$

The overall theme in the present study may provide an understanding that loneliness among older service users challenged the home care nurses to identify both who was lonely and how to meet their needs. The findings of previous studies that have included home care nurses have demonstrated that health care professionals have experienced several barriers when encountering loneliness among older people, such as how to interpret and verbalize loneliness. ${ }^{18,25}$

The home care nurses in the present study stressed that their preconceptions about who was lonely did not always turn out to be correct. Another study ${ }^{18}$ found that health care professionals' interpretations of older people's experiences of loneliness were often based on guesswork. Our informants often experienced older service users communicating loneliness in an indirect way. Other studies ${ }^{26-28}$ have shown that when talking about negative emotions, older people may express themselves in a vague manner.

The above examples may stress the importance of asking older people about loneliness directly; however, our study revealed that this was difficult for the nurses. This type of question assumed time resources that the nurses did not have, and they felt that they should have something more to offer. Being lonely was perceived as a taboo subject to talk about; as a result, it may be claimed that these people were not allowed to talk about their loneliness. However, in another study, ${ }^{25}$ some older people expressed they did not talk to anyone else about their loneliness because they feared that letting others know how they felt would increase their suffering because they would get stigmatized as being lonely. The home care nurses in our study seemed to have similar ideas. Conversely, it has been argued that when health care professionals did not talk about loneliness with older people, these professionals perceived it as a taboo subject. $^{25}$ 
One aspect revealed in a previous study ${ }^{18}$ was that health care professionals sometimes distanced themselves and felt inadequate whenever they encountered lonely older people. It was argued that these health care professionals might face their own fears and insecurities by talking about challenging issues such as loneliness. This is also an interesting aspect to note regarding the nurses' reservations in our study. It has also been emphasized that home care nurses must be aware of and open to whatever is revealed in their conversations with older people. ${ }^{28}$ Talking may provide a therapeutic function and relieve negative emotions among the elderly; thus, paying more attention to communication in home care settings is needed. ${ }^{28}$ This may also highlight the need for home care nurses to reflect on and discuss challenging issues with their colleagues. ${ }^{18}$ Our study showed that time resources for collective professional reflections were perceived as being both limited and desired. Dealing with reflections and having colleagues' support may open ways for professionals to become more aware of their communication styles with older people who are lonely. ${ }^{18}$ It might also be argued that nurses with advanced skills in geriatric nursing should be hired to support the nursing staff, as this competence may strengthen their understanding of the older people and promote the quality of holistic care. ${ }^{29}$

Although the nurses in our study reported that they were mostly reserved when communicating directly with the older service users about loneliness, they did not neglect these needs in their everyday work. They presented their nursing care as a combination of working, talking, being conscious of nonverbal communication, and paying attention when performing their practical tasks, all of which are important.

However, our findings revealed a major barrier for meeting lonely older people's needs. Loneliness among older people was generally not accepted as a need for nursing care when decisions for nursing tasks were made. This may be an outcome of the purchaser-provider model where these decisions are made at another level of the organization. This model may reduce home care nurses' power to influence the planning of service users' care. ${ }^{30}$ That loneliness among older persons is clearly associated with varied health factors ${ }^{3,9}$ underline the importance of addressing loneliness in home care nursing. The fact that practical work was given preference in the decision-making process activated thoughts among nurses that they were not providing enough help to meet lonely older people's needs. Sometimes these nurses had to rearrange their daily work schedule if they assessed that they had to spend more time with an individual service user. Therefore, although they worked without being completely bound to the written policies, they sometimes did so with a feeling of using "illegal" time. Moreover, these nurses also tried to find ways to get more time for their lonely older service users by masking these needs as physiological challenges. A previous study ${ }^{16}$ identified both value conflict and moral distress when home care nurses felt that they had to struggle to provide high-quality nursing care. Our findings also indicate these conflicts based on the nurses' experiences. They valued having a good relationship with their older service users, and some of them reported situations where they were personally affected by these relationships. The philosopher Knud Ejler Løgstrup ${ }^{31}$ argued that impartial relationships between people based on concern alone cannot exist because there is always a personal relationship involved. Pauly et $\mathrm{al}^{32}$ described that moral distress in health care has been defined as when individuals have difficulties in both realizing professional values in practice and choosing to follow rules or one's conscience. This type of distress may highlight the conflicted emotional state among nurses when they visited older service users they perceived as being lonely. Further, moral distress may arise when they experience that they cannot act in accordance with what they believe is the right thing to do because of organizational factors. ${ }^{33}$ The organizational structure for practicing nursing was presented in our study as a major barrier to meeting lonely older people's needs. On the other hand, the idea of nursing understood as care for meeting an individual's needs that is based on a holistic perspective tended to overwhelm the home care nurses. These findings indicate that the nurses also perceived the structure of the purchaser-provider setting as a kind of protection against becoming overloaded in their nursing practice. Loneliness among older people was a theme that activated their reflections on a nurse's role in a home care setting, which might indicate a kind of ambivalence in their professional attitudes to meeting such needs.

The organizational structure for practicing nursing may also limit nurses' professional performance. Consequently, this structure might exempt the nurses from the responsibility of meeting the lonely older people's needs. The purchaserprovider setting in home care nursing may mandate nurses to perform practical task-oriented jobs for service users and then leave them. ${ }^{16}$ The nurses in our study seemed to be affected by lonely seniors' situations. They thought they could provide only limited services to these people beyond encouraging them to spend time at their local day care center. There seemed to be a potential for reinforcing nurses' knowledge about how to involve volunteers in their work to relieve 
loneliness. Additionally, the home care nurses called for stronger teamwork with other health care professionals. It might be argued that nursing leaders have a responsibility to focus on the home care nursing role in the primary health care system. They might have the key positions needed to stand up to organizational policies. Further, they may act as the cornerstones for motivating and supporting nurses in practicing high-quality nursing care. ${ }^{29}$ However, understanding and addressing the fact that loneliness among older people is a health-related challenge may be the fundamental premise for meeting these needs in a home care setting. ${ }^{3,19}$

\section{Strengths and Limitations}

Few home care nurses participated in the focus group interviews, which may be considered as a limitation. Five home care nurses could not participate due to their heavy workload. This shows the difficulty of recruiting informants who are on active duty. On the other hand, one of the study's strengths was that all the included nurses actively participated in the focus group interviews. It is well known that not everyone is comfortable sharing their experiences in front of others. ${ }^{34}$ However, the researchers found that there was an inclusive atmosphere in the focus group interviews that let all the informants speak freely about their different thoughts and experiences. Another strength was that the informants were recruited from the home care services belonging to two different municipalities. A qualitative study might include the potential to achieve a nuanced and holistic understanding of the home care nurses' perceivements. ${ }^{34}$ However, if the number of informants and number of home care services had been larger, the findings may have revealed nurses' broader experiences about older people's loneliness. Likewise, it would have been desirable if any male nurses had participated to produce more varied findings.

Two researchers performed the data collection for each focus group interview, which created the opportunity to ask relevant follow-up questions. The analysis of the interview texts was based on a well-known content analysis method, ${ }^{20}$ and all the steps in this analysis were strictly followed. The first author performed the analysis and discussed all the steps with the other researchers. This may have functioned as quality assurance in order to take an unbiased approach to the data, which is important when considering the study's validity. Moreover, despite the small sample, the collected data was found to be rich; as a result, saturation was obtained. It is also important to be aware of the researchers' preconceptions. Although the researchers previously worked in health care settings for older people as nurses and have $\mathrm{PhD}$ degrees with a specialization in geriatrics, they tried to remain unbiased with regard to the data. The fact that quotations are used to support the findings, and that these findings are supported by other similar research studies, strengthens the reliability of our study.

The findings are not generalizable to other homecare nurses. However, it may be suggested that the findings can be transferred to groups of homecare nurses in similar settings, but it is up to the reader to assess its transferability. ${ }^{20}$

\section{Conclusion}

The home care nurses perceived loneliness among older people as a complex and subjective phenomenon. The findings provide insight into how loneliness among these individuals challenged the home care nurses to communicate with their older service users about loneliness and meet these people's needs. The organizational structures around home care nursing were perceived as being the major barriers to meeting these needs, thereby activating nurses' conflicted thoughts, feelings, and solutions in their everyday work. Loneliness among older people stimulated nurses' reflections on the purpose of their nursing role in a home care setting.

Addressing loneliness among older people as a healthrelated challenge is important and these individuals' needs should be included in organizational structures for practicing home care nursing. The nursing leaders of home care settings must be aware of nurses' experiences regarding loneliness among older service users and promote nurses' acquisition of knowledge about loneliness to meet the needs of older people. Professional guidance and reflections should also be promoted among home care nurses so that they will be able to communicate and meet lonely older people's various needs. Further research is essential to promote the nurses' role in meeting the needs of lonely older home-dwelling people.

\section{Data Sharing Statement}

The interview data will not be shared since the informants are guaranteed full anonymity.

\section{Acknowledgments}

We will thank the nurses who contributed to this study. The study was supported by Faculty of Health and Sport Sciences, University of Agder, Norway. 


\section{Disclosure}

The authors report no conflicts of interests.

\section{References}

1. Dahlberg L, Andersson L, Mckee KJ, Lennartsson EC. Predictors of loneliness among older women and men in Sweden: a national longitudinal study. Aging Ment Health. 2015;19(5):409-417. doi:10.1080/ 13607863.2014.944091

2. Djuanovic I, Sorjonen K, Peterson U. Association between depressive symptoms and age, sex, loneliness and treatment among older people in Sweden. Aging Ment Health. 2014;19(6):560-568. doi:10.1080/13607863.2014.962001

3. Tomstad S, Dale B, Sundsli K, Sævareid HI, Söderhamn U. Who often feels lonely? A cross-sectional study about loneliness and its related factors among older home-dwelling people. Int $J$ Older People Nurs. 2017;12(4):e12162. doi:10.1111/opn.12162

4. Sjöberg M, Beck I, Rasmussen BH, Edberg A-K. Being disconnected from life: meanings of existential loneliness as narrated by frail older people. Aging Ment Health. 2017;22(10):1357-1364.

5. Taube E, Jakobsson U, Midlöv P, Kristensson J. Being in a bubble: the experience of loneliness among frail older people. $J$ Adv Nurs. 2015;72(3):631-640. doi:10.1111/jan.12853

6. Peplau LA, Miceli M, Morash B. Loneliness and self-evaluation. In: Peplau LA, Perlman D, editors. Loneliness: A Sourcebook of Current Theory, Research, and Therapy. New York: Wiley; 1982:135-151.

7. Sønderby LC, Wagoner B. Loneliness: an integrative approach. J Integr Soc Sci. 2013;3(1):1-29.

8. Weiss RS. The Experience of Emotional and Social Isolation. Cambridge, MA: MIT Press; 1973.

9. Donavan NJ, Blazer D. Social isolation and loneliness in older adults: review and commentary of a national academies report. Am J Geriatr Psychiatry. 2020;28(12):1233-1244. doi:10.1016/j.jagp.2020.08.005

10. Boeckxtaens P, De Graaf P. Primary care and care for older persons: position paper of the European forum for primary care. Qual Prim Care. 2011;19(6):369-389.

11. Holm SG, Mathiesen TA, Sæterstrand TM, Brinchmann BS. Allocation of home care services by municipalities in Norway: a document analysis. BMC Health Serv Res. 2017;17(1):673. doi:10.1186/s12913-017-2623-3

12. Norwegian Ministry of Health and Care Services. Future care. Report no. 29 to the storting (2012-2013). Oslo, Norway; 2013. Available from: https://www.regjeringen.no/contentassets/34c8183cc5cd43e2b d341e34e326dbd8/en-gb/pdfs/stm201220130029000engpdfs.pdf. Accessed October 15, 2020.

13. United Nations. Living arrangements of older persons: a report on an expanded international dataset. ST/ESA/SER.A/407. New York: United Nations; 2017. Available from: https://www.un.org/en/devel opment/desa/population/publications/pdf/ageing/ LivingArrangements.pdf. Accessed October 15, 2020.

14. Norwegian Ministry of Health and Care Services. Samhandlingsreformen - rett behandling - på rett sted. [The coordination reform - proper treatment - at the right place and right time]. Report no. 47 (2008-2009). Norwegian; 2009. Available from: https://www.regjeringen.no/contentassets/d4f0e16ad32e4bbd8d8ab5 c21445a5dc/no/pdfs/stm200820090047000dddpdfs.pdf. Accessed November 15, 2020.

15. Norwegian Ministry of Health and Care Services. Lov om kommunale helse - og omsorgstjenester m.m. (helse- og omsorgstjenesteloven). [Act related to health and care services, etc. (Health and care services act)]. Norwegian; 2011. Available from: https:// lovdata.no/dokument/NL/lov/2011-06-24-30?q=Helse \%20og\% 20omsorgstjenestelovenOsloNorway. Accessed November 15, 2020.
16. Tønnesen S, Nordtvedt P, Førde R. Rationing home-based nursing care: professional ethical implications. Nurs Ethics. 2011;18 (3):386-396. doi:10.1177/0969733011398099

17. Tønnesen S, Førde R, Nordtvedt P. Fair nursing care when resources are limited: the role of patients and family members in Norwegian home-based services. Policy Polit Nurs Pract. 2009;10(4):276-284. doi:10.1177/15271527154409357108

18. Sundström M, Edberg A-K, Rämgård M, Blomqvist K. Encountering existential loneliness among older people: perspectives of health care professionals. Int J Qual Stud Health Well-Being. 2018;13 (1):1474673. doi:10.1080/17482631.2018.1474673

19. Macleod S, Musich S, Parikh RB, Hawkins K, Keown K, Yeh CS. Examining approaches to address loneliness and social isolation among older adults. J Aging Geriatr Med. 2018;2:1. doi:10.4172/ 2576-3946.1000115

20. Graneheim UH, Lundman B. Qualitative content analysis in nursing research: concepts, procedures and measures to achieve trustworthiness. Nurse Educ Today. 2004;24(2):105-112. doi:10.1016/j.nedt.2003.10.001

21. Beauchamp TL, Childress JF. Principles of Biomedical Ethics. 7th ed. Oxford, UK: University Press Inc; 2013.

22. World Medical Association Declaration of Helsinki. Ethical principles for medical research involving human subjects; 2018. Available from: https://www.wma.net/policies-post/wma-declaration-ofhelsinki-ethical-principles-for-medical-research-involving-humansubjects/. Accessed November 15, 2020.

23. Tong A, Sainsbury P, Craig J. Consolidated criteria for reporting qualitative research (COREQ): a 32-item checklist for interviews and focus groups. IJQHC. 2007;19(6):349-357. doi:10.1093/intqhe042

24. Graneheim UH, Lundman B. Experiences of loneliness among the very old: the Umeå $85+$ project. Aging Ment Health. 2010;14 (4):433-438. doi:10.1080/13607860903586078

25. Lykke S, Handberg C. Experienced loneliness in home-based rehabilitation: perspectives of older adults with disabilities and their health care professionals. Glob Qual Nurs Res. 2019;6:1-12. doi:10.1177/ 2333393619831661

26. Hafskjold L, Sundling V, Eide H. Nursing staff's responses to thematic content of patients' expressed worries: observing communication in home care visits. BMC Health Serv Res. 2018;18(1):597. doi:10.1186/s12913-018-3390-5

27. Höglander J, Eklund JH, Eide H, Holmström IK, Sundler AJ. Registered nurses' and nurse assistants' responses to older persons' expressions of emotional needs in home care. $J$ Adv Nurs. 2017;73 (12):2923-2932. doi:10.1111/jan.13356

28. Sundler AJ, Höglander J, Eklund JH, Eide H, Holmström IK. Older persons' expressions of emotional cues and concerns during home care visits: application of the Verona coding definitions of emotional sequences (VR-CoDES) in home care. Patient Educ Couns. 2017;100 (2):276-282. doi:10.1016/j.pec.2016.09.009

29. Boman E, Glasberg A-L, Levy-Malmberg R, Fagerström L. Thinking outside the box: advanced geriatric nursing in primary health in Scandinavia. BMC Nurs. 2019;18(1):25. doi:10.1186/s12912-019-0350-2

30. Dale B, Hvalvik S. Administration of care to older patients in transition from hospital to home care services: home nursing leaders' experiences. J Multidiscip Healthc. 2013;6:379-389. doi:10.2147/ JMDH.S51947

31. Løgstrup KE. The Ethical Demand. Notre Dame: University of Notre Dame Press; 1997.

32. Pauly BM, Varcoe C, Storch J. Framing the issues: moral distress in health care. HEC Forum. 2012;24(1):1-11. doi:10.1007/s10730-012-9176-y

33. Lamiani G, Borghi L, Argentero P. When health care professionals cannot do the right thing: a systematic review of moral distress and its correlates. J Health Psychol. 2017;22(1):51-67. doi:10.1177/ 1359105315595120

34. Polit DF, Beck CT. Nursing Research: Principles and Methods. 7th ed. Philadelphia, PA: Lippincott Williams \& Wilkins; 2004. 


\section{Publish your work in this journal}

The Journal of Multidisciplinary Healthcare is an international, peerreviewed open-access journal that aims to represent and publish research in healthcare areas delivered by practitioners of different disciplines. This includes studies and reviews conducted by multidisciplinary teams as well as research which evaluates the results or conduct of such teams or healthcare processes in general. The journal

covers a very wide range of areas and welcomes submissions from practitioners at all levels, from all over the world. The manuscript management system is completely online and includes a very quick and fair peer-review system. Visit http://www.dovepress.com/testimonials. php to read real quotes from published authors. 